\title{
CAD/CAM in dentistry - a critical review
}

\author{
Adriana Postiglione Bührer Samra ${ }^{a}$, Eduardo Morais ${ }^{b}$, Rui Fernando Mazurc, \\ Sergio Roberto Vieira ${ }^{c}$, Rodrigo Nunes Rached ${ }^{\circ}$
}

\begin{abstract}
Objective: The CAD/CAM process in Dentistry describes an indirect restoration designed by a computer (Computer Aided Design) and milled by a computer assisted machine (Computer Aided Machined). It can be divided into three different steps: data acquisition, indirect restoration design and construction of the prosthesis itself. This paper relates the state of art of the CAD/CAM systems in dentistry and some of the concerns and special cares that can interphere to optimize their results. Yet, it stablish some considerations about the role of CAD/CAM systems in the present and near future of the dental practice.

Methods: The Scientific Electronic Library Online (SCIELO) and biomedical journal literature of the National Library of Medicine (MEDLINE/PubMed) electronic databases were used to search the literature from 2004 to 2013.

Conclusion: There are advantages to using CAD/CAM in Dentistry: the new materials are esthetically pleasing and durable; there is increased efficiency in laboratory processing; quick fabrication of the restoration; and quality control of restorations such as fit, mechanical durability and predictability. These advantages will ultimately benefit our patients.
\end{abstract}

Key words: Dental prosthesis; Computer-aided design; Software; Review

\section{CAD/CAM na odontologia - uma revisão crítica}

\section{RESUMO}

Introdução: O sistema CAD/CAM na Odontologia pode ser descrito como uma restauração indireta desenhada por um computador (Computer Aided Design) e usinada por um dispositivo computadorizado (Computer Aided Machined). O processo pode ser dividido em três etapas: aquisição dos dados, desenho da restauração indireta e a construção da prótese propriamente dita. Este artigo relata o estado da arte dos sistemas $\mathrm{CAD} / \mathrm{CAM}$ e algumas das preocupações e cuidados especiais que podem otimizar seus resultados. Além disso, são estabelecidas algumas considerações sobre o papel a ser desempenhado pelos sistemas CAD/CAM no presente e no futuro próximo na prática odontológica.

Metodologia: As bases de dados Scientific Electronic Library Online (SCIELO) e biomedical journal literature of the National Library of Medicine (MEDLINE/PubMed) foram utilizadas para pesquisar a literatura, no period compreendido entre 2004 e 2013.

Conclusão: Há vantagens em utilizar CAD/CAM em Odontologia: esteticamente aceitaveis; aumento da eficiência no processamento laboratorial; fabricação rápida da restauração; controle de qualidade de restaurações tais como ajuste, durabilidade mecânica e previsibilidade. Estas vantagens beneficiam os pacientes.

Palavras-chave: Prótese dentária, Software, Revisão
Universidade Estadual de Ponta Grossa (UEPG) Departament of Dentistry, Ponta Grossa, PR, Brasil ${ }^{\mathrm{b}}$ Universidade Positivo (UP), Departament of Dentistry, Curitiba, PR, Brasil

C Pontifícia Universidade Católica de Paraná (PUC- PR),School of Health and Bioscience, Curitiba, PR, Brasil 


\section{INTRODUCTION}

The CAD/CAM process in Dentistry describes an indirect restoration designed by a computer (Computer Aided Design) and milled by a computer-assisted machine (Computer Aided Machined) [1]. The first system introduced was developed by Duret and colleagues in 1971, but was not widely used, mostly because of the lack of accuracy of digitizing, computer power and materials, etc [2]. Thus, in the next decade, Mormann and Brandestini developed the CEREC system in Zurich, Switzerland. The name CEREC means CEramic REConstrution. CEREC was responsible for the exponential increase in CAD/CAM technology throughout the world. However, in computer-aided design of restorations there are several potentially accuracycompromising aspects: data acquisition, determination of the margin in the digital model, and restoration design [3]. The manufacturing process also presents its own challenges, such as the accuracy of restoration fit, especially when it has to reproduce complex surfaces, and surface irregularities caused by cutting paths [4]. Therefore, based on these concerns, the systems have been improved over the last two decades. CAD/CAM has now become a well-accepted technology in most modern dental laboratories, and for some enterprising clinicians, at the chair-side, as well [5].

The CAD/CAM process can be divided into three different steps: data acquisition, indirect restoration design and construction of the prosthesis itself [6]. Each step requires special care to optimize the results. In addition, is important to emphasize that the steps work independently, although the images captured will determine the construction of the digital model, making it possible to design the indirect restorations to be built [5]. When the indirect restoration design has been completed, data can be saved and accessed at any stage of the process, meanwhile they can be sent to the milling unit. At this point, a software program defines the building process of the indirect restoration [7].

\section{DATA ACQUISITION}

The images and/or dimensions of the prepared teeth and related structures can be captured using a conventional cast model or, more recently, directly, intra-orally. Both processes may be performed by contact scanners, optical scanners, 3D microtomography (MCT) and nuclear magnetic resonance (NMR) [2,5], digital cameras - CCD, associated with visible light or LASER Small sized scanners may also be used, allowing versatile use in dental offices and prosthesis laboratories [6].

Optical scanners have the advantages of providing rapid data acquisition, while contact scanners tend to provide superior copy acuity [6], although both types present satisfactory results. However, one study has demonstrated that not only was the reproducibility of optical scanners comparable with that of contact scanners (a difference of around $10 \mu \mathrm{m}$ ), but that there was similar acuity between the two types [8]. There are various types of optical scanners available, which may be used intra and extra-orally. In general, the optical scanner works with an active triangulation process, in which a sensor captures the patterns of light and shade projected. The receptor of the sensor interprets the changes in depth in terms of distances, generating the tridimensional image [9]. However, as digitalization of the data is obtained by the reflection of light captured by a PSD sensor, diffusion may interfere in the precision of the digitalized images [6]. This may be minimized, for example, with the help of sprays that must be applied on the surfaces to be copied, especially in the oral cavity [10]. The need for performing this procedure must be considered in the choice of the data acquisition process.

Although 3D MCT and NMR are reported in the literature as being tools for digitizing images for $\mathrm{CAD} / \mathrm{CAM}$ restorations, they are not routinely used. It has been related that, even though, at this moment these tools are not wide spread in the clinical field, they tend to gain popularity [11].

CCD Digital cameras (charged coupled device) associated with projections of white, blue light, or LASER have become a trend in data acquisition $[2,6,12]$. The light source is projected onto the structures to be digitalized, and a CDD camera captures the images. This technology dispenses with the stages of impression taking and modeling, and is therefore a faster procedure [1] and provides greater biosafety. Moreover, the camera delegates the task of data acquisition to the dentist, and no longer to the laboratory technician. The process appears to be more precise, because it does not incorporate small errors resulting from the distortions of impression taking and modeling materials, although there is little literature available to confirm this information [2]. When several dental elements must be reproduced, and components of implants inserted into soft tissues, data acquisition may be performed on plaster models. Although digital impression seems to have several advantages, it is not applicable to all prosthetic cases [13].

\section{DATA PROCESSING/INDIRECT RESTORATION DESIGN}

From the data acquired, the image is transferred with the help of a software program, to a data processing center, where the images of the dental preparations will form a tridimensional network, the precision of which is related to the devices used in the foregoing processes. These images will be used in the design of the prosthetic infrastructure, or in the indirect restoration itself (onlay, inlay, etc). Both the software programs and hardware available for the process have developed enormously over the last 20 years. However, the small amount of literature available, detailing their mechanisms and functioning may be attributed to market secrets [6]. The software programs offer various and intuitively-used tools for manipulating the images. Current $\mathrm{CAD} / \mathrm{CAM}$ systems provide sophisticated features to detect preparation margins, direct positioning of connectors and pontics and to allow essential planning of both form and support, considering strength and esthetics [14]. Software 
programs follow the same steps used by dental technicians to build an indirect restoration, such as: margin selection, block-out of undercuts, and placement of a die spacer for a cement layer [12]. However, final adjustments will be determined by the dental technician, assisted by the software.

Each system and material has different characteristics. Some software programs, for instance, enable shade evaluation in the digital model, predicting esthetics results, such as CEREC system. When partially sintered Zirconiabased material is used, for example, the size of the digital framework is analogically enlarged by approximately $20 \%$ and $25 \%$ in comparison with the original dimensions at the design stage, due to the shrinkage occurring after the final sintering [14]. Whereas, when fully sintered zirconiabased material is milled, there is no change in volume, so the framework design exhibits the exact tooth preparation dimensions. The software program enables the technician to choose the internal fit, according to the expected cement line.

\section{COMPUTER ASSISTED MANUFACTURING}

\section{a) Close $x$ Open Systems}

The three stages related above, in spite of being interrelated, may be performed in an open or close system. If closed systems are used, the manufacturer presents equipment capable of performing each of the stages of the process in a sequential and inter-related manner. In these cases, there is greater coherence in the data processing in all the stages. (e.g., Procera and Lava systems). Initially, the systems were developed in this manner; that is to say, the manufacturer presented the technology for all the stages. However, the laboratory that would acquire this type of system would be restricted to using only the materials made available by the manufacturer [12]. With the advancement in the technology, tools began to be established for each of the stages in an independent manner, making it possible to integrate different scanners/software and milling machines.

When the data acquisition process may be sent to any data processing center for designing and machining the indirect restoration, it is called an open system. Many contact optical scanners and digitalizers allow this association with milling units. There is a trend to digitalize the data in a standard template library (STL) system, and thus, any CAM system that accepts STL files can produce the indirect restorations [12].

The greatest advantage of the open systems is that a larger number of professionals have access to the technology.

\section{b) Subtractive $x$ Additive Processes}

Indirect restorations can be manufactured by both subtractive and additive processes. Although additive manufacturing tends to be the trend for the future, nowadays, the subtractive process is wide-spread throughout the world in dentistry.
This technology uses a computerized milling machine loaded with CAD data. The CAM machine shapes the bulk material, of which even the size is chosen by the system.

The simplest milling process uses MAD/MAM technology, in which the restoration is initially produced manually in wax or composite resin. The pattern obtained is then placed in the pantographic machine, so that simultaneously one arm reads the pattern (copying arm) while the other arm (cutting arm) performs milling of the block of restorative material. This method is considered high precision copying [12]. A recent study demonstrated that better passive fit is achieved with copy-milled frameworks and anatomic contour restorations than with $\mathrm{CAD} / \mathrm{CAM}$ double-layer restorations [14].

Whereas, with the $\mathrm{CAD} / \mathrm{CAM}$ method, right after finalizing the design of the indirect restoration, the system processes the data, selects the size and the position of the block of restoration material, in order to obtain the best results with the least waste of time and material, and beings the machining process. The milling procedure may be performed with the use of carbide or diamond burs in a dry environment or under water coolant, when needed. In the Decsy system (Digital Process LTD, Japan) the machining process begins with coarser grain burs (3.0mm in diameter), followed by finishing burs (1.6mm in diameter) [6]. The burs are changed automatically, and so is inversion of the position of the part being machined. Whereas, the COMET system (Steinbichler, Germany) has interchangeable cutters driven by computerized speed and multiple axes capable of building up an accurate copy of $10 \mu \mathrm{m}$ marginal fit [16]. On the other hand, the Cadim system (Advance, Japan) has only one $2.0 \mathrm{~mm}$ bur [17].

The number of axes is one of the important parameters, because the restoration geometry depends on the number of positions of access the bur may obtain during machining. The more axes, the more detailed the restoration morphology can be. Another aspect to point out is stabilization of the block of restorative material in the machine. In general, the block is stabilized from one of its sides. Thus, the milling unit has no access to that point, and therefore, at that point, milling must be manual. The milling unit of the Everest system (KaVo, Germany) developed the technique of stabilization of the block by means of acrylic resin, allowing complete milling of the computerized restoration. However, it should also be reported that in this process it is necessary to reposition the block manually, with acrylic resin, in order to perform machining in all the axes [1].

Another factor to be considered is the milling path. It can be radial from the center of the crown or straight in one direction, the latter path being unfavorable for cutting the details of the crown [17]. Although statistically significant differences in surface roughness between systems have been observed, they could be acceptable for polishing when referring to titanium. When zirconia is used, the milling paths could be even more important, because the trace lines 
combined with microcracks can influence the survival rate of restorations [3].

More recently, in addition to the subtractive process, which is well-known and well-accepted in dental labs and practice nowadays, there have been descriptions in the literature of a trend towards an additive process [3,5].

There are advantages to this type of manufacturing such as the ability of the technique to create fine details of complex internal geometries [5]. Another advantage of these techniques is the absence of waste. Instead of using bulk restorative material that is milled until it becomes a framework, the restoration is constructed layer by layer. On the other hand, bulk material usually presents the best mechanical properties, of high-strength materials with no voids [3].

Although subtractive CAD/CAM dental systems are less time consuming and less human-labor demanding, the process does not easily allow mass production such as crowns and bridges, since only one part can be machined at any one time [5]. Whereas, the additive process, such as laser-sintering, can be considered an industrial production process where high productivity meets consistent quality standards at reduced costs.

There are several additive techniques, such as stereolithography (SLA), fused deposition modeling (FDM), selective electron beam melting (SEBM), laser powder forming (SLM or SLS), inkjet printing. New techniques are becoming competitive with traditional manufacturing techniques in terms of price, speed, reliability, and cost of use, along with an emerging software industry to enable more effective use of the technology [5]. Mechanical properties have been extensively studied in recent times. However, the accuracy of the restorations obtained, as well as their microstructure must be verified, in addition to their compatibility with the veneering material [18].

The SLM or SLS technique can be highlighted. This technology is based on slicing the restoration digital design and scanning the patterns of each layer, which are computer produced successively from a melted metal powder. A controlled laser beam melts non-precious powder alloys, specially titanium and cobalt-chromium and is called Selective laser melting (SLM). If it is used with porcelain powder it is called Selective laser sintering (SLS). At least three companies are commercially using this technology. BEGO industries developed BEGO MEDIFACTURING ${ }^{\circledR}$ $\mathrm{CAD} / \mathrm{CAM}$ systems that can produce diverse frames, irrespective of whether they are caps, crowns or bridges, using precious metal, $\mathrm{CoCr}$, titanium-made based on CAD data. Porcelain has been studied for fitting into this system [19].

The Sirona Company developed EOSINT M270. This direct metal laser-sintering machine fuses metal powder into a solid part by melting it locally, using a focused laser beam. According to the manufacturer, in the process, $20 \mu \mathrm{m}$ layers are created, controlled by sophisticated hard and software, leading to frames with high accuracy and detailed resolution, good surface quality and excellent mechanical properties [19].

\section{LIMITATIONS}

The systems available at present provide tools to minimize any eventual limitations. There has been a description in literature of deficient shaping, especially occlusal, that could jeopardize the esthetic and mechanical properties of the material. However, modern systems have improved milling machines with more axes and cutting paths, thereby increasing the definition of restorations.

As there have been increasing clinical indications for this technology lately, new concerns arise. When multiple unit bridges are used, one must be concerned about the factor of passive fit [15] and possibility of repair. If metalceramic appliances are used, soldering can be done to prevent the development of strain. With the CAD/CAM technique there are two situations to be analyzed. The long-extension bridges are milled in one piece, which might lead to strain development, especially in angledtype bridges $[2,6]$. The second situation is with regard to the veneering technique, which may also lead to strain development. In spite of the precision of the framework, the application of ceramic veneering results in an increase in strain development [15].

The use of monolithic zirconia presents some limitations as well, such as slow crack formation and the direct impact of zirconia on masticatory forces, causing wear of the antagonist teeth [14].

Optical image acquisition seems to be a trend for the future, but at present, there is a huge limitation on capturing images for multiple elements prosthesis [20].

Finally, the cost and the accessibility of the technology must be considered. Not all the systems and restorative materials are available in all countries. Not all the systems are compatible. One has to investigate which systems and materials are available and compatible with the clinical applications before making a choice.

\section{CONCLUSIONS}

Irrespective of the clinical application, the $\mathrm{CAD} / \mathrm{CAM}$ technology has been shown to have better mechanical performance, because preconceived structures are involved.

There are advantages to using CAD/CAM in Dentistry: the new materials are esthetically pleasing and durable; there is increased efficiency in laboratory processing; quick fabrication of the restoration; and quality control of restorations such as fit, mechanical durability and predictability $[21,22]$. These advantages will ultimately benefit our patients [2]. There are new materials and techniques launched on market on a daily basis, most of them adding something new to restorative procedures.

The future is digital, but in this "technological era" we, professionals of dentistry, must be aware of the developments, and whether they will improve dental treatment quality and longevity, based on scientific evidences and serious researches. 


\section{REFERENCES}

1. Correia ARM, Sampaio Fernandes JCA, Cardoso JAP, Leal-Da-Silva CLC CAD-CAM: informatics applied to fixed prosthodontics. Rev Odontol UNESP. 2006;35(2):183-9.

2. Miyazaki T, Hotta Y. CAD/CAM systems available for the fabrication of crown and bridge restorations. Aust Dent J [Review]. 2011 June;56 Suppl 1:97-106. https://doi.org/10.1111/j.1834-7819.2010.01300.x

3. Rekow ED, Silva NR, Coelho PG, Zhang Y, Guess P, Thompson VP. Performance of dental ceramics: challenges for improvements. J Dent Res. 2011 Aug;90(8):937-52. https://doi.org/10.1177/0022034510391795

4. Reich S, Gozdowski S, Trentzsch L, Frankenberger R, Lohbauer U Marginal fit of heat-pressed vs. CAD/CAM processed all-ceramic onlays using a milling unit prototype. Oper Dent. 2008 Nov-Dec;33(6):644-50. https://doi.org/10.2341/07-162

5. Van Noort R. The future of dental devices is digital. Dent Mater [Review]. 2012 Jan;28(1):3-12. https://doi.org/10.1016/j. dental.2011.10.014

6. Miyazaki T, Hotta Y, Kunii J, Kuriyama S, Tamaki Y. A review of dental CAD/ CAM: current status and future perspectives from 20 years of experience. Dent Mater J [Review]. 2009 Jan;28(1):44-56. https://doi.org/10.4012/ dmj.28.44

7. Beuer F, Schweiger J, Edelhoff D. Digital dentistry: an overview of recent developments for CAD/CAM generated restorations. Br Dent J [Review]. 2008 May 10;204(9):505-11. https://doi.org/10.1038/sj.bdj.2008.350

8. Persson A, Andersson M, Oden A, Sandborgh-Englund G. A threedimensional evaluation of a laser scanner and a touch-probe scanner. J Prosthet Dent. 2006 Mar;95(3):194-200. https://doi.org/10.1016/j. prosdent.2006.01.003

9. Caparroso Perez CB, Marín Munoz DV, Echavarría Velasquez A. Adaptación marginal y ajuste interno en estructuras de zirconia-ytria elaboradas con los sistemas CAD/CAM Procera y Cerec in-Lab. Rev Fac Odontol Univ Antioq. 2011 Jan-June;22(2):186-97.

10. Aboushelib MN, Elmahy WA, Ghazy MH. Internal adaptation, marginal accuracy and microleakage of a pressable versus machinable ceramic laminate venners. J Dent 2012 Aug; 40(8):670-7. https://doi.org/10.1016/j. jdent.2012.04.019

11. Kamegawa M, Nakamura M, Fukui Y, Tsutsumi S, Hojo M. Direct 3-D morphological measurements of silicone rubber impression using micro-focus X-ray CT. Dent Mater J. 2010 Jan;29(1):68-74. https://doi. org/10.4012/dmj.2009-021
12. Helvey GA. Press-to-zirconia: a case study utilizing cad/cam technology and the wax injection method. Pract Proced Aesthet Dent. 2006 Oct;18(9):547-53; quiz 54

13. Wiersema EJ, Kreulen CM, Creugers NH. [The conventional and the digital impression method for single-unit and multi-unit fixed dental prostheses]. Ned Tijdschr Tandheelkd. 2013 July-Aug;120(7-8):401-10.

14. Koutayas SO, Vagkopoulou T, Pelekanos S, Koidis P, Strub JR. Zirconia in dentistry: part 2. Evidence-based clinical breakthrough. Eur J Esthet Dent. [Review]. 2009 Winter;4(4):348-80.

15. Karl M, Graef F, Wichmann M, Krafft T. Passivity of fit of CAD/CAM and copy-milled frameworks, veneered frameworks, and anatomically contoured, zirconia ceramic, implant-supported fixed prostheses. Prosthet Dent. 2012 Apr;107(4):232-8. https://doi.org/10.1016/S00223913(12)60067-5

16. Willer J, Rossbach A, Weber HP. Computer-assisted milling of dental restorations using a new CAD/CAM data acquisition system. J Prosthet Dent. 1998 Sept;80(3):346-53. https://doi.org/10.1016/S00223913(98)70136-2

17. Hotta Y, Miyazaki T, Fujiwara T, Tomita S, Shinya A, Sugai Y, et al. Durability of tungsten carbide burs for the fabrication of titanium crowns using dental CAD/CAM. Dent Mater J. 2004 June;23(2):190-6. https://doi.org/10.4012/ dmj.23.190

18. Kruth JP, Badrossamay M, Yasa E, Desckers J, Thijs L, Van Humbeeck J. Part and material properties in selective laser melting of metals. XVI International Simposium on Electromachining 2010.

19. Sirona the dental company [homepage] CAD/CAM materials: global site, 2013 [Cited on 2013 sep 15] Available from: http://www.sirona.com/en/ products/digital-dentistry/cad-cam-materials?tab $=253$

20. Fasbinder DJ. Chairside CAD/CAM: an overview of restorative material options. Compend Contin Educ Dent. 2012 Jan;33(1):50, 2-8

21. Giordano R, Mclaren EA. Ceramics overview: classification by microstructure and processing methods. Compend Contin Educ Dent. 2010 Nov-Dec;31(9):682-4, 6, 8 passim; quiz 98, 700.

22. Yüksel E, Zaimoglu A. Influence of marginal fit and cement types on microleakage of all-ceramic crowns. Bras Oral Res. 2011 May-June; 25(3):261-6 